\title{
A PERSONALIDADE DO ESTADO
}

Até aqui tratamos do Estado como organismo politico do corpo social, isto é, como uma substancia subsistente, com constituição propria, com orgams proprios, funcções proprias e operações proprias. (Vide Revista da Faculdade, vol. XVIII, 1910, pags. 45 a 59). Vamos agora tratar do Estado como substancia individual; e, para maior clareza, convém preliminarmente reproduzir a noção ontologica da substancia.

Substancia é o ente a que convém ser em sí e não em outro como em sujeito. A substancia póde ser simples ou composta: simples é aquella que nem consta de partes physicas, nem póde ser resolvida em partes physicas, por exemplo, o anjo, a alma humana; composta é aquella que resulta de muitos principios ou partes substanciaes, como o homem, o bruto, os corpos, cujo composto constitúe uma só natureza. A substancia póde ser considerada como completa ou como incompleta: completa é aquella que constitúe um ente integral de sua natureza, por exemplo, o homem, a massa de ouro; incompletas são aquellas que se concebem como partes de um todo integral ou que se ordenam para constituir um composto substancial, taes são o ramo da arvore, as mãos, etc, e a materia e a fórma nas cousas corporeas. 
A substancia é um dos dez generos supremos ou categorias, segundo a classificação de Aristoteles. Comquanto o universal e o particular estejam em todos os generos, isto é, tanto na substancia, como na quantidade, na qualidade, na relação, na acção, na paixão, no tempo, no lugar, na situação e no habito, - comtudo o individual se acha no genero da substancia: a substancia individúa-se por si mesma, ao passo que os accidentes individuam-se na substancia.

O termo individuo exprime uma idéa relativamente opposta á especie e ao genero. Dizemos relativamente opposta, porque esta opposição não é contradictoria, nem contraria, nem privativa: assim, o individuo Pedro não deixa de pertencer á especie homem e ao genero animal; assim, este objecto, em que estou agora assentado, é um individuo da especie cadeira e do genero mobilia. Individuo é todo e qualquer objecto determinado de modo que todas as suas determinações não possam simultaneamente convir a outro; indivi$d u o$, em summa, é tudo que não póde dividir-se sem destruir-se.

O principio de individuação é aquelle principio intrinseco pelo qual a substancia, indivisa em si, distingue-se de qualquer outra na mesma especie. Este principio intrinseco não se confunde com as extrinsecas notas individuantes, que são accidentes pelos quaes as substancias, já individuadas, se distinguem. Estes signaes ou notas são consideradas em numero de sete, segundo o seguinte verso:

Forma, figura, locus, tempus, stirps, patria, nomen. Hœe ea sunt septem, quœ non habet unus et altera.

Nas substancias corporeas, o principio da individuação é a materia assignalada pela quantidade. A fórma não individúa, porque dá á especie e o genero, que são attributos communs.

A substancia individual, completa e incommunicavel, emquanto é sujeito das operações proprias, denomina-se-supposto; a substancia individual, completa, incommunicavel, emquanto é sujeito das operações pro- 
prias, denomina-se pessoa, quando é racional. A pessoa. é, pois, uma substancia individual de natureza racional.

A substancia completa e incommunicavel, ou seja simples supposto ou seja pessoa, deve ser não sómente individual, mas tambem subsistente. Subsistencia é a perfeição por cuja força a natureza já completa e singular, torna-se propria e de direcção propria (sui ipsius et sui juris), ou, como dizem, autonoma. Triplice é a propriedade da substancia subsistente: (1)

1. Possúe o seu ultimo complemento; porque, então, não sómente é o principio do qual decorrem suas operações, isto é, sua natureza fixa, como tambem é o principio que as opera, isto é, sujeito activo e sujeito passivo, ou, como dizem, - tota in se et maximè per se.

2. ${ }^{\circ}$ Existe por causa de si; isto é, não por causa de outro supposto, do qual seja assumida.

3. Opera por causa de si; assim, ao homem attribúe-se tudo o que corpo ou alma age, pois igualmente dizemos - eu ando, eu sinto, eu penso; assim, ao Estado se attribúe tudo o que, no exercicio das respectivas funcções, é praticado pelos orgams de seus poderes politicos.

\section{I I}

Cada corpo social, comquanto instituido com muitos individuos de natureza humana, é constituido com orgams proprios e funcções proprias, de modo que converte-se em uma substancia, tão unica, tão individual, tão completa, tão incommunicavel, como o corpo animado de cada homem. Os membros do corpo social, unidos por um nexo estavel, coherentes entre si, são contidos por um só espirito, uno spiritu continetur, ut corpora plura non soluta, diz SENECA, (2) formando

(1) Farges, Philos. Eschol., I, Ontol., n. 110.

(2) Uma individualidade collectiva de animaes irracionaes, diz Schutzenberger, forma uma agregação, mas não um corpo; uma individualidade collectiva de animaes racionaes, emquanto nāo animada por um espirito proprio e por direcção propria, póde ser uma agregação ou mesmo uma congregação, mas não ć um corpo, nern mesmo uma corporaçāo. 
assim um individuo, visto que este corpo social é uma unidade indissoluvel, que distingue-se de todos os outros e que não póde dividir-se sem destruir-se; por outro lado, quando este corpo social é sujeito das operações proprias e o seu organismo é composto de orgams racionaes para funcções racionaes, a sua natureza autonomica e racional, qualidade intrinseca dessa substancia individual, caracterisa a sua personalidade. (3)

O corpo social de um paiz tem o seu principio intrinseco de individuação, menos no territorio designado pela quantidade extensiva, do que na população, designada pelo calcule da quantidade numerica.

Alguns, em relação á sociedade politica, exigem como materia, para o principio intrinseco de individuação, um territorio fixo; mas, isto não é um principio intrinseco, é uma nota extrinseca, que contribúe para a subsistencia de um corpo social já individuado. Assim, os Hebreus já formavam um corpo social, sob regimen e fim politico, durante o exodo, antes de se fixarem na Palestina, onde, então, se tornaram subsistentes.

Esta subsistencia não accrescenta uma nova substancia ao corpo social, porque este corpo já está individuado; esta subsistencia pela qual o corpo social é constituido com orgams proprios e com funcções proprias e com acção(4) em territorio fixo, é um modo da mesma substancia, modo que lhe confere o attributo de Estado.

(3) Schutzenibrger, Les lois de l'ordre social, Livr. I, cáp. XVII.

(4) Dizemos - acção - e não - dominio. O chamado dominio eminente é uma dessas muitas illusōes ou ficções que têm perturbado a sciencia do Direito Publico. Um Estado exerce o seu poder sobre todo o territorio ; mas, não se segue d'ahi que, no sentido do Direito Civil, exerça dominio como direito de propriedade.

Como bem explica o nosso Lafayette, Direito Internacional, I, $\$ 74,-$ o territorio, em que um Estado exerce o seu poder, está dividido em parcellas que pertencem já a subditos nacionaes ou estrangeiros que as tenham adquirido, já a sociedades ou corporaçōes. já ao proprio Estado como cousas do seu patrimonio publico ou privado. A sujeição do territorio á soberania exprime uma relação juridica puramente politica e consiste nisto - que o territorio e tudo que nelle existe, pessoas e cousas, ficam sob a 
Das notas individuantes, ou signaes extrinsecos pelos quaes se manifesta a individualidade (fórma, figura, lugar, tempo, estirpe, patria, nome), as mais caracteristicas são a fórma do seu organismo, a sua situação local e o seu nome. A individualidade deste corpo social reveste a personalidade pela racionalidade do seu organismo politico e pela autonomia do seu funccionamento.

acção absoluta e exclusiva dos poderes do Estado, acção que o Estado não exerce como proprietario na accepçāo do Direıto Civil, mas conno poder, imperio o.1 jurisdicção, no sentido de Direito Publico.

Em consequencia, a determinação definitiva de limites territoriaes entre nossos Estados Federados compete, na forma do art. 34 n. 10 da Constituição da Republica, não ao Poder Judiciario, mas ao Congresso Nacional. Entretanto; tivemos occasiāo de contemplar uma acção civil entre os Estados de Santa Catharina e do Paraná, em que se pretende reivindicação e demarcação, como si se tratasse de um direito de propriedade....; e sóbe de ponto a nossa surpreza, quando vêmos que o Supremo Tribunal Federal julgou-se competente para conhecer de tal acção.

Esta nossa surpreza chega ao cumulo, quando vemos que o Congresso Nacional julga-se dispensado do encargo que the confere o cit. art. 34 n. 10 da Constituição da Republica, isto é, de aresolver definitivaminte sobre os limites dos Estados entre sin, e approva, por Dec n. 2699 de 25 de Setembro de 1912, um corivenio entre os Estados de Minas-Geraes e Espirito Santo, para solução de suas questões de limites em tribunal arbitral. Comprehende-se que, nas questões de limites entre Estados scberanos, seja possivel recorrer ao juizo arbitral, porque não ha poder constituido para resolvel-os definitivamente; mas, na federação das nossas antigas provincias, tal como ficou constituida pela Constituição de $2+$ de Fevereiro de 1901. a attribuição de sresolver definitivamente sobre os limites dos Estados entre si - é de funcção do poder legislativo nacional, funcção privativa, que não póde, de modo algum, ser delegada. O Dec. n. 2699 de 25 de Setembro de 1912 é um acto flagrantemente inconstitucional.

Affirmando a incompetencia absoluta do Supremo Tribunal Federal nesta questão de limites, nāo nos parece que possamos estar em erro: 1.0 Porque a acção politica territorial dos Estados Federados nem mesmo toi fixada pelos proprios Estados, mas pelo art 2.0 da Constituição da Republica; 2.0 Porque a mesma Constituição da Republica, art. 34 n. 10, confere sómente ao Congresso Nacional a attribuiçāo de sresolver definitivamente sobre os limites dos Estados entre si»: $30^{\circ}$ Porque a mesma Constituição da Republica. art. 64, em relaçăo ao territorio. sómente reconheceu como do dominio dos Estados, as minas e terras devolutas, o que importa a negação do pretendido dominio émint'nt' dos Estados Federados sobre todo o respectivo territorio. 


\section{$-36-$ \\ IV}

Portanto, o Estado, como substancia individual, é um supposto, que reveste a personalidade, porque, sendo o Estado um organismo composto de orgams racionaes para funcções racionaes, a racionalidade é uma qualidade intrinseca deste organismo. Nem ha necessidade de ficção para attribuir ao Estado a personalidade.

Cada Estado, quer nas suas relações politicas, quer nas suas relações patrimoniaes e contractuaes, quer nas suas relações internas, quer nas suas relações externas, é uma substancia individual de natureza racional; é, portanto, uma pessoa. Nas suas relações de propriedade, quer patrimoniaes, quer contractuaes, cada Estado toma restrictamente a denominação de pessoa juridica, em correlação opposta ás suas relações de poder publico, em que é considerado como pessoa politica; nas suas relações de poder soberano, formadas com outros Estados igualmente soberanos, cada Estado é considerado como pessoa internacional.

Convém notar que esta triplice manifestação da personalidade do Estado - não o transforma em tres pessoas distinctas: é uma só e mesma pessoa, uma só e mesma substancia individual, considerada em tres relações differentes. Por outra: os adjectivos - politica, juridica, internacional - unidos ao substantivo complexo - pessoa do Estado, não exprimem caracteristicos individuaes diversos, porém relações de uma só e mesma substancia individual, posto que, quanto ao modo de agir, sejam subordinadas a regras differentes. E' a these de Chrysippo:-- "Dois caracteristicos individuaes não pódem se combinar no mesmo ser». Assim como a pessoa humana é conveniente comsigo mesma ou identica nos varios momentos de sua existencia, assim a pessoa do Estado é identica em todas as suas relações: a identidade da pessoa humana só depende da identidade do corpo, da alma e da subsistencia; a identidade da pessoa do Estado só depende da identidade do corpo social, do organismo constituido e da subsistencia. Emquanto, pois, um individuado corpo social tem um organismo politico subsistente, a sua personalidade é uma e a mesma, qualquer que seia a diversidade de 
suas relações, ainda que subordinada a regras differentes quanto ao modo e fórma de agir. A extensão da personalidade dos Estados, quaesquer que sejam as suas manifestações, depende do seu gráu de subsistencia, isto é, está ligada ás relações em que se póde manifestar a sua autonomia.

As acções são dos suppostos; e, portanto, das pessoas, quando os suppostos são de natureza racional. A razão disto é que a acção é um effeito e, como effeito, deve ser refundida no principio de que procede. $\mathrm{Na}$ natureza racional, a pessoa é quem intenta o fim da acção e quem primeiramente age; isto é, a pessoa é quem dispõe do principio activo; o orgam é apenas um meio para exercer a funcção e praticar a operação.

$\mathrm{Na}$ acção temos de considerar o principio activo, a funcção, o orgam e a operação. O principio activo, que é o poder ou força de agir, é da causa primeira ou causa efficiente principal; a funcção é a causa final especifica da acção da força de agir; o orgam é toda a causa efficiente instrumental, ou instrumento immediatamente ligado á causa efficiente principal; a operação é o movimento produzido pelas causas efficientes principal e instrumental, em uma causa material, mediante uma causa formal, para uma causa final.

A acção é sempre um ente relativo á substancia individual donde procede. Assim, a acção politica do Estado, isto é, a acção legislativa, a acção executiva, a acção judiciaria, effeitos dos poderes politicos, são relatıvas á pessoa do Estado, posto que as funcções desses poderes sejam exercidas pelos legisladores, pelos governadores e seus agentes, e pelos juizes; a acção privada do Esstado, isto é, a acção civil, effeito dos seus direitos de propriedade e das suas obrigações contractuaes, são relativas á mesmá pessoa do Estado, posto que, nas estipulações e nos litigios, elle funccione por mandatarios perante officiaes de fé publica, perante testemunhas e perante juizes e auxiliares da justiça. Aquellas acções regem-se pelo Direito Publico; estas regem-se 
pelo I)ireito Privado; mas, quer aquellas, quer estas, são acções da mesma pessoa do Estado, posto que para relações differentes.

A extensão das relações pessoaes do corpo social, assim como a extensão das relações de qualquer pessoa physica, clepende sempre do seu gráu de autonomia.

A soberania é o principio mais elevado da autonomia, porque corresponde ao espirito que torna indissoluvel a unidade de um corpo social; ella, como a alma humana, está tota in toto corpore et tota in qualibet parte, isto é, toda em todo o corpo social e toda em qualquer parte do corpo; ou, como diz Aristoteles, ut omnes partem habeant in principatu, non ut singuli, sed ut universi, isto é, para que todos tenham parte no governo, não como cada um, mas todos por um e um por todos. O organismo politico de um Estado é sempre uma delegação da soberania; mas, si este organismo é simples, é a elle delegada toda a soberania e a consequente autonomia completa; si este organismo é composto, a autonomia de cada parte organica é tão relativa quanto a delegação é relativa aos limites das funcções, isto é, tanto quanto, no organismo geral, os organismos parciaes estiverem subordinados á coordenação e á supra-ordenação, para a unidade indissoluvel de todo o corpo social. (5)

Jō̃o Mendes Junior

(5) Confira-se o meu pamphleto-Soberania, autonomia, federaçẫo. 